\title{
Educação especial na perspectiva da educação inclusiva: desafios da implantação de uma política nacional ${ }^{1}$
}

\section{Special education on the perspective of inclusive education: implementation challenges of a national policy}

\author{
Mônica de Carvalho Magalhães Kassar²
}

\begin{abstract}
RESUMO
Este artigo propõe-se a analisar os desafios do oferecimento de uma educação especial dentro da atual política de educação inclusiva do Governo Federal. Para tanto, apresenta um breve histórico a respeito das diretrizes educacionais baseadas na separação de alunos, que sustentaram a educação especial no Brasil desde sua implantação até a adoção de uma política de matrículas em massa de crianças com ou sem deficiências nas escolas públicas. Discute as condições de implantação da proposta do Governo Federal de um "sistema educacional inclusivo", que conta com um suporte de atendimento educacional especializado para complementar e suplementar a educação escolar. Apresenta também um estudo de caso em uma escola pública municipal considerada como representativa de sucesso e aponta para limites da materialização da política proposta. Conclui ressaltando os impasses estabelecidos pelas escolhas do Governo Federal para a atual política educacional.
\end{abstract}

Palavras-chave: política educacional; política de educação inclusiva; educação especial.

${ }^{1}$ Este texto é fruto de pesquisa realizada com apoio do Conselho Nacional de Desenvolvimento Científico e Tecnológico (CNPq). Registro meu agradecimento à professora Dra. Gilberta Jannuzzi que gentilmente cedeu sua biblioteca particular para coleta de material.

${ }^{2}$ Doutora em Educação. Docente da Universidade Federal de Mato Grosso do Sul (UFMS, Campus do Pantanal. Contato: monica.kassar@pq.cnpq.br 


\begin{abstract}
This article aims to analyze the challenges of a special education policy within the current inclusive education policy adopted by the Brazilian federal government. Firstly, the paper presents a brief history of the educational guidelines based on the separation of pupils, which supported special education since its beginning until the adoption of a universalization method, with the adoption of mass enrollments of children with or without disabilities in public schools. It goes on to discuss the conditions of implementation of an "inclusive education system", proposed by the federal government, which is supported by a specialized educational service designed to complement and supplement school education. It then presents a case study, considered as a "success case" in a municipal public school, and points out the limits regarding the materialization of the policy proposed. The conclusion emphasizes the impasses established by the federal government choices related to the present educational policy.

Keywords: educational policy; inclusive education policy; special education.
\end{abstract}

Nos últimos anos, muitos educadores de escolas públicas brasileiras têm se surpreendido com a presença de alunos com deficiências matriculados em suas turmas, em diferentes níveis de ensino. Essa situação é resultante de uma política denominada de educação inclusiva, que tem sido implantada explicitamente desde 2003. O objetivo deste artigo é analisar os desafios do oferecimento de uma educação especial dentro da atual política de educação inclusiva do Governo Federal.

\title{
Breve história apagada
}

No Brasil, o atendimento educacional direcionado às pessoas com deficiências foi construído separadamente da educação oferecida à população que não apresentava diferenças ou características explícitas que a caracterizasse como "anormal". Dessa forma, a educação especial constituiu-se como um campo de atuação específico, muitas vezes sem interlocução com a educação comum. Esta separação materializou-se na existência de um sistema paralelo de ensino, de modo que o atendimento de alunos com deficiência ocorreu de modo incisivo em locais separados dos outros alunos ${ }^{3}$.

\footnotetext{
${ }^{3}$ Observa-se que esta não foi uma prática apenas da educação especial brasileira, mas comum em países da Europa e da América em geral.
} 
A formação de uma educação especial brasileira deu-se dentro de um contexto de pouca atenção à educação pública em geral. Schwarcz (1998 apud VEIGA, 2008) informa que o recenseamento do ano de 1872 registrou $84 \%$ da população brasileira como analfabeta. Essa restrita atenção em relação à educação pode ser explicada por vários motivos, dentre os quais, ressaltamos: 1. A organização econômica do Brasil nos períodos da Colônia e Império não necessitava da alfabetização e da instrução da massa trabalhadora (grande parcela da população vivia na zona rural e a economia baseava-se, inicialmente, na exploração de bens naturais e, posteriormente, na produção de monoculturas em grandes latifúndios); 2. Havia pouca atenção à educação também por parte de nossos colonizadores, pois registros de Portugal $^{4}$ apontam que naquele país, no século XIX, grande parte da população não tinha acesso à instrução e era analfabeta; 3 . Apesar de a educação ser prevista a "todos os cidadãos" (na Constituição de 1824), a massa de trabalhadores era composta de maioria escrava ${ }^{5}$. Com a República, a preocupação com a instrução tornou-se mais marcante, embora acanhada, de modo que a taxa de matrícula da população brasileira foi crescendo gradativamente nos centros urbanos durante o século XX. Romanelli (1989) mostra a evolução populacional e de escolaridade brasileira na primeira metade do século XX. Em 1920, a taxa de escolarização era de 8,99\% da população e em 1950 chega a 26,15\% (cf. ROMANELLI, 1989).

Nesse período, pesquisas desenvolvidas nos países Europeus apontavam a preocupação com os alunos que frequentavam a educação pública, mas não se beneficiavam totalmente dela ${ }^{6}$. Alfred Binet (1857-1911) e Theodore Simon (1872-1961) iniciaram seus trabalhos de mensuração da inteligência das crianças francesas matriculadas em suas escolas. Publicaram, em 1905, uma escala de inteligência, cujo objetivo foi medir o desenvolvimento da inteligência das crianças de acordo com a idade (idade mental). Nesse momento, acreditava-se que a separação de alunos "normais" e "anormais" traria benefício para todos no processo educativo. Monarcha (2007) informa que, no Brasil, tal escala foi aplicada sob a orientação de Clemente Quaglio (1872-1948), na capital paulista. Os resultados foram publicados na obra $A$ solução do problema pedagógico social da educação da infância anormal de inteligência no Brasil, em 1913.

A preocupação em identificar "normais" e "anormais" foi difundida na ciência médico-pedagógica de vários países. Como exemplo dessa preocupa-

${ }^{4}$ Informações registradas por Costa (1868, p. 179 in: FERREIRA, 1975).

5 Dados apresentados por Basbaum (1982, p. 93) indicam que, no início do século XIX, praticamente $1 / 3$ da população brasileira era escrava.

${ }^{6}$ É importante registrar que esses países atingiram a universalização da instrução obrigatória nesse período, de modo que Hobsbawn (1989) afirma que de 1870 a 1914, no que se refere à educação, para a maioria dos países europeus foi a era da escola primária. 
ção, apresentamos o trecho de um artigo do italiano Ugo Pizzoli (1863-1934), publicado no Brasil em 1914, em revista de educação da época:

$\mathrm{O}$ aspecto externo (atitude geral, a fisionomia, o vestuário, a postura espontânea) caracteriza e revela a condição psicológica da criança [...] O primeiro cuidado do professor será distinguir o typo intelligente normal médio do typo débil de espírito (imbecilidade, deficiências por paradas de desenvolvimento, atrasos, etc.) (PIZZOLI, 1914, p. 2)7.

A prática de identificação de possíveis alunos "anormais" era solicitada ao professor para organização de salas de aulas homogêneas. Rocha (1979) identifica duas obras fundamentais para a educação dos "anormais" nesse momento: Educação da Inteligência Anormal no Brasil, de Clemente Quaglio e Tratamento e educação das crianças anormais de inteligência, de Basílio de Magalhães, ambas dos anos de 1910. É interessante ressaltar que, diferentemente da tendência da época, os estudos de Basílio de Magalhães concluíram que a convivência de crianças anormais e normais era benéfica, sob o ponto de vista emocional e econômico (MAGALHÃES, s/d).

Apesar de registros da existência de matrículas de alunos com deficiências em escolas privadas e estaduais desde o final do século XIX ${ }^{8}$, é possível dizer que, no país, a organização de instituições especializadas foi a referência para o atendimento a essas pessoas. Em 1933, o decreto que instituiu o código da educação no estado de São Paulo deixou clara essa preferência e indicou a implantação de classes especiais quando isso não fosse possível:

Parte VII

Da educação especializada

Art. 824

Dos tipos de escolas especializadas:

a) escolas para débeis físicos

b) escolas para débeis mentais

c) escolas de segregação para doentes contagiosos

d) escolas anexas aos hospitais

${ }^{7}$ Neste artigo, manteremos a grafia encontrada nos documentos pesquisados.

${ }^{8}$ Como apresentado no início deste texto, em Brasil (1975), há o registro de classes para atendimento de alunos com deficiências física, visual, mental, auditiva e problemas de comportamento desde 1887 e nas primeiras décadas do século XX. 
e) colônias escolares

f) escolas para cegos

g) escolas para surdos-mudos

h) escolas ortofônicas

i) escola de educação emendativa dos delinquentes.

Onde não for possível a instalação de escolas especializadas autônomas [...] serão organizadas classes para esses fins especiais nos grupos escolares. (DECRETO 5.884, de 1933)

Sob a supervisão de organismos públicos de inspeção sanitária, a organização das classes especiais públicas e o encaminhamento para instituições especializadas ocorreram a partir da justificativa científica de separação dos alunos "normais" e "anormais". Nesse período, o Brasil estava passando por um processo de transformação econômica com a instalação de seu parque industrial e o início do movimento de crescimento das cidades, que passaram a receber a população que vivia anteriormente no campo ${ }^{10}$. Com isso, ocorreu o aumento progressivo do número de matrículas nas escolas brasileiras (como mostrado anteriormente). A frequência da população pobre nas escolas públicas ficou mais evidente ${ }^{11} \mathrm{e}$ as leis da época registraram a preocupação com o estado dessa população:

\section{Art. 826}

As escolas de débeis físicos se destinam às crianças desnutridas ou em crescimento em atraso as quais convenha regime especial de trabalho escolar, com o fim de reintegrá-las na normalidade física (DECRETO 5.884, de 1933)

${ }^{9}$ Jannuzzi (1985) e Bueno (2004) lembram que a preocupação com a deficiência mental refletia a preocupação com a higiene da população. O Art. 825 do decreto de 1933 estipula: "O recrutamento de alunos para essas diferentes escolas, com exceção das indicadas à letra "h", do artigo anterior, deverá ser feito pelo Serviço de Higiene e Educação Sanitária Escolar, que solicitará cooperação do Serviço de Psicologia e das várias instituições ou serviços especializados do Departamento de Educação".

${ }^{10}$ O IBGE, no ano de 1977, publicou um levantamento da população brasileira desde a primeira parte do século XX até aquela data. Nesse documento podemos verificar que, em 1940, o país possuía uma população de 41.236 .315 habitantes, sendo que $31 \%$ viviam em zona urbana e $69 \%$ na zona rural. Já em 1970 , dos 93.139 .037 brasileiros, 56\% viviam nas cidades, enquanto que $44 \%$ na zona rural. Portanto, em apenas 30 anos, houve uma reconfiguração urbana no país.

${ }^{11}$ Veiga (2008) analisa a frequência da população pobre desde os primórdios da instrução pública brasileira. 
A preocupação científica de identificação e tratamento dos "anormais" também estava presente na formação de Helena Antipoff ${ }^{12}$ (1892-1974), que a partir dos anos de 1930, marcou a educação especial brasileira. Em 1932, Helena Antipoff, que veio para o Brasil a convite do governo de Minas Gerais, criou a Instituição Pestalozzi de Minas Gerais. Esse Instituto impulsionou a educação especial naquele estado e influenciou as ações ligadas à educação em todo o país. À época, as crianças deveriam ser agrupadas seguindo critérios estabelecidos pela aplicação de testes de inteligência:

Conforme dissemos, o primeiro passo no sentido de individualizar o ensino é agrupar os alunos, tendo em vista o ritmo de desenvolvimento mental. O processo mais empregado hoje em dia é a seleção das crianças e sua concentração em classes homogêneas de valor forte, médio e fraco, organizadas em escalas de idades mentais.

São numerosos os testes de inteligência global, de aplicação individual e coletiva, destinados às crianças em idade escolar.

$[\ldots]$

O critério do Quociente Intelectual, como a experiência demonstrou, é superior ao simples critério da idade mental, para a formação de classes homogêneas [...] (BOLETIM N. 14 PUBLICAÇÃO DA SECRETARIA DE EDUCAÇÃO - MG, 1934 apud ANTIPOFF, 1974, p. 56)

Esses critérios serviram tanto para a organização de classes homogêneas das escolas públicas quanto para a formação das classes especiais:

As classes organizadas, considerando os vários critérios apontados acima, passaram a ser denominadas: classes $\mathrm{A}, \mathrm{B}, \mathrm{C}, \mathrm{AB}, \mathrm{BC}, \mathrm{Br}, \mathrm{Cr}$, e ainda $\mathrm{D}$ e $\mathrm{E}$.

$[\ldots]$

As classes D e E foram chamadas Classes Especiais. Nelas, foram colocados os excepcionais de toda a espécie, que freqüentavam a escola pública: retardados mentais, deficientes sensoriais, e de linguagem, crianças com distúrbios de motricidade, orgânicos (classe D) e com desvios de comportamento (Classe E). (BOLETIM N. 14 PUBLICAÇÃO

${ }^{12}$ Helena Antipoff era de origem russa e aplicou, no Brasil, os conhecimentos adquiridos na Universidade de Genebra, na Suíça, com o pedagogo Edouard Claparède. Sobre a organização da Sociedade Pestalozzi, ver http://www.fenasp.org.br/quemsomos.htm. 
DA SECRETARIA DE EDUCAÇÃO - MG, 1934 apud ANTIPOFF, 1974, p. 58)

Vemos, pelo decreto do estado de São Paulo e pelo Boletim da Secretaria de Educação do estado de Minas Gerais, ambos dos anos de 1930, que na história da educação brasileira a separação foi constituindo-se como preferência e não exceção. Dessa forma, a separação de crianças foi (e talvez ainda seja) uma prática pedagógica proposta para a educação em geral. Partindo do pressuposto de adequação dos espaços segregados e com escassas escolas públicas no país, durante a primeira metade do século XX, pais e profissionais de pessoas com deficiências passaram a se organizar e formar instituições privadas de atendimento especializado. Essas instituições acabaram ocupando um lugar de destaque na Educação Especial brasileira, chegando a confundir-se com o próprio atendimento público, aos olhos da população, pela gratuidade de alguns serviços. Assim surgiram a Pestalozzi do Brasil no Rio de Janeiro em 1945, a Pestalozzi de Niterói em 1948, ambas com o apoio e colaboração de Helena Antipoff ${ }^{13}$. Seguindo essa tendência, em 1954, também no Rio de Janeiro, a primeira Associação de Pais e Amigos dos Excepcionais - APAE - foi organizada e se desenvolveu ocupando "o espaço vazio da educação especial como rede nacional" (SILVA, 1995, p. 36). Essas e outras instituições alcançaram no Brasil uma grande amplitude, de forma que Jannuzzi (1997) afirma que muitas decisões da política da educação especial são frutos de pressões dessas associações. Mesmo quando o governo brasileiro passa a legislar a Educação Especial para todo o país, na LDB (Lei de Diretrizes e Bases) de 1961, não deixa de contemplar a existência e o financiamento das instituições particulares especializadas (cf. ART. 89 da LDB/1961).

Apesar de a escolarização obrigatória brasileira ser de apenas quatro anos, referente ao antigo curso primário, até a década de 1960, sua cobertura era pequena, reduzida a uma pequena parcela da população. Um relatório da UNESCO, datado de 1963 e publicado no Brasil apenas em 1982, confirmou essas informações, alertando que, enquanto muitos países europeus já haviam atingido a universalização no ensino obrigatório e registravam grande expansão do ensino de $2^{\circ}$ grau, outros países não conseguiam "escolarizar mais do que a minoria das crianças em idade de freqüentar a escola primária" e estavam

${ }^{13}$ A Sociedade Pestalozzi do Brasil registra que o movimento pestalozziano começou em 1925, por um casal de educadores. O trabalho foi iniciado com crianças que não conseguiam acompanhar o ensino regular em Canoas, RS. 
"longe de haver ensinado toda a população a ler e escrever" (UNESCO, 1982, p. 11). Após o golpe militar de 1964, a legislação sobre as diretrizes e bases da educação nacional foi revista e, em 1971, a Lei Educacional n. ${ }^{\circ} 5.692$ passou a obrigatoriedade da escolarização brasileira para oito anos, com a instituição do $1^{\circ}$ grau. Em relação à Educação Especial, a Lei 5.692/71, no Artigo $9^{\circ}$, definiu a caracterização dos alunos de Educação Especial como aqueles "que apresentem deficiências físicas ou mentais, os que se encontrem em atraso considerável quanto à idade regular de matrícula e os superdotados". A partir desse momento, registrou-se um aumento significativo do número de classes especiais nas escolas estaduais nos diferentes municípios brasileiros (cf. BRASIL, 1975). Pela especificação da Lei 5.692/71, foi atribuída à educação especial a responsabilidade de atendimento de crianças sem a necessidade de diagnóstico de deficiência ${ }^{14}$.

Em 1973, para a implantação do Centro Nacional de Educação Especial CENESP ${ }^{15}$ - foram convidados como assessores técnicos James J. Gallagher, da Universidade de Carolina do Norte, e David M. Jackson, da Superintendência da Educação Pública em Springfield, Illinois, ambos dos Estados Unidos da América ${ }^{16}$. O presidente da República era Emílio Garrastazu Médici (1969-1974) e o discurso corrente sobre a educação era de investimento para a formação de recursos humanos e para o desenvolvimento do país (JANNUZZI, 2004). Gallagher (1974) defendia que:

[...] um retardado e internado entre as idades de 10 e 60 anos, nos Estados Unidos, para ser cuidado, custa ao Estado US\$ 5.000 ao ano, ou um total de US\$250.000 durante toda a sua vida. O mesmo indivíduo recebendo educação e tratamento adequados pode tornar uma pessoa útil e contribuir para a sociedade. Assim, o custo extra que representam os custos extras com educação especial pode ser compensador quanto a benefícios econômicos maiores. Há um estudo segundo o qual um adulto retardado e educado poderia ganhar US\$ 40 para cada dólar extra despendido com sua educação. (GALLAGHER, 1974, p. 100)

${ }^{14}$ Desde a década de 1970, trabalhos como os de Schneider (1977) e Paschoalick (1981) mostraram que grande parte dos alunos que frequentavam as classes especiais para deficientes mentais era formada por crianças que, em princípio, deveriam ser incorporadas pelo ensino regular.

${ }^{15}$ Órgão ligado ao Ministério da Educação para regular, disseminar, fomentar e acompanhar a Educação Especial no Brasil. Hoje, esse papel cabe à Secretaria de Educação Especial do MEC (Ministério da Educação e Cultura).

${ }^{16}$ Gallagher e Jackson foram consultores técnicos que, com apoio da USAID (United States Agency for International Development), colaboraram com o Grupo de trabalho do Ministério da Educação e Cultura encarregado da montagem do Projeto Prioritário n 35 do Plano Setorial de Educação e Cultura do MEC, em 1972 (PIRES, 1974). 
A citação acima aponta para a incorporação da Teoria do Capital Humano na educação especial na década de 1970, que já fazia parte do discurso educacional brasileiro (SAVIANI, 2008), e que a justificativa para a implantação de tais serviços pautou-se, ao menos em parte, na sua função econômica (ARRUDA; KASSAR; SANTOS, 2006), evidenciando a preocupação com a relação custo-benefício direcionando a política educacional. Nesse momento, o CENESP divulga os princípios de normalização e integração ${ }^{17}$ das pessoas com deficiências na educação que passam a marcar a educação especial brasileira.

\section{Educação Especial e a garantia do direito à educação pública}

A Constituição Federal de 1988 configurou-se como um novo estatuto jurídico para o país. Contando com o envolvimento da sociedade civil organizada, essa Constituição caracteriza-se por uma ênfase nos direitos sociais e pelo estabelecimento dos princípios de descentralização e municipalização para a execução das políticas sociais, inclusive na educação, que passa a ser considerada direito subjetivo. Constitucionalmente implicado, o Governo Federal desde a década de 1990 tem implantado e/ou fomentado um conjunto de ações nas várias áreas dos serviços públicos como parte do sistema de proteção social. No entanto, também a partir dessa década, o governo brasileiro passou claramente a adequar-se à organização do mercado mundial globalizado na expansão do modelo econômico capitalista. Desde o governo de Fernando Collor de Mello (1990-1992), tornou-se constante um discurso sobre a modernização da economia com críticas à ação direta do Estado, principalmente nos setores de proteção social. Na continuidade dessa tendência, Fernando Henrique Cardoso (19941998; 1998-2002) assumiu o governo brasileiro e seu discurso sustentou-se na construção de uma "terceira via", expresso desde a aprovação do Plano Diretor da Reforma do Aparelho de Estado (BRASIL, 1995). Nessa reforma, setores importantes como a educação e a saúde deveriam ter como corresponsáveis o "terceiro setor", através da ação das instituições públicas não estatais.

O quadro político e econômico constituído no Brasil, a partir do final dos anos 1990, passa a estabelecer uma tensão: de um lado o estabelecimento constitucional de políticas sociais universais (da educação, saúde), que teriam

${ }^{17}$ Esses princípios referem-se ao movimento de mainstreaming, originário da Dinamarca e que se espalhou pelo mundo, contra a internação em massa das pessoas com deficiências em instituições asilares. 
como pressuposto a ação direta do Estado; de outro um contexto de regulação e restrição econômica, sob um discurso de solidariedade e de necessidade de retração do setor público (com a participação do terceiro setor).

Em 1990, o Brasil participou da Conferência Mundial sobre Educação para Todos, em Jomtien - Tailândia -, e coube ao país, como signatário da Declaração Mundial sobre Educação para Todos, a responsabilidade de assegurar a universalização do direito à Educação. Desse compromisso decorreu a elaboração do Plano Decenal de Educação para Todos, concluído em 1993, que tinha como objetivo assegurar, até o final de sua vigência, a todos os brasileiros "conteúdos mínimos de aprendizagem que atendam necessidades elementares da vida" (BRASIL, 1993, p. 13).

O movimento de Educação para Todos atinge, de certa forma, as pessoas com deficiências. No entanto, parece-nos que as propostas direcionadas a essa população têm também alguns elementos específicos. Mel Ainscow, consultor da UNESCO, faz um histórico interessante da Educação Especial no mundo e afirma que nos anos 1970 mudanças importantes ocorreram em muitos países, que culminaram com as proposições atuais ${ }^{18}$. Ainscow (1995) apresenta um levantamento realizado por esse órgão na década de 1980 em 58 países, em que foi verificado que a organização da Educação Especial dava-se predominantemente em escolas especiais separadas, que atendiam um número reduzido de alunos. A partir dessas informações, o relatório da UNESCO indica que diante das "proporções da demanda e os escassos recursos disponíveis, as necessidades de educação e formação da maioria das pessoas deficientes não pode satisfazer-se unicamente em escolas e centros especiais" (UNESCO, 1988 apud AINSCOW, 1995, p. 18). A partir dessa constatação, o autor afirma que

[...] é necessário introduzir mudanças tanto nas escolas especiais como nas regulares [...] Há muitas indicações de que em um número elevado de países de todo o mundo a integração é um elemento central na organização da educação especial [...]. Esse projeto parece adequado para os países do Terceiro Mundo, dada a magnitude das necessidades e as inevitáveis limitações de recursos disponíveis (AINSCOW, 1995, p. 18)

Os argumentos registrados no relatório da UNESCO em 1988 são os mesmos encontrados em um documento que marcou a Educação Especial no Brasil:

${ }^{18}$ Um fato importante foi a elaboração do Relatório Warnock, na Inglaterra, em 1978, que difundiu o conceito de "necessidades educacionais especiais". 
A Declaração de Salamanca, fruto da "Conferência Mundial sobre Necessidades Educativas Especiais: acesso e qualidade”, ocorrida na Espanha, em 1994:

A experiência, sobretudo nos países em via de desenvolvimento, indica que o alto custo das escolas especiais supõe, na prática que só uma pequena minoria de alunos [...] se beneficia dessas instituições...

[...] Em muitos países em desenvolvimento, calcula-se em menos de um por cento o número de atendimentos de alunos com necessidades educativas especiais. A experiência [...] indica que as escolas integradoras, destinadas a todas as crianças da comunidade, têm mais êxito na hora de obter o apoio da comunidade e de encontrar formas inovadoras e criativas de utilizar os limitados recursos disponíveis (DECLARAÇÃO DE SALAMANCA, 1994, p. 24-25)

Essa declaração enuncia que diante do alto custo em manter instituições especializadas as escolas comuns devem acolher todas as crianças independentes de suas condições físicas, intelectuais, sociais, emocionais, linguísticas ou outros. Dois anos mais tarde, a Lei de Diretrizes e Bases da Educação Nacional em 1996 - LDB/96 - é promulgada, propondo a adequação das escolas brasileiras para atender satisfatoriamente a todas as crianças. Diferenças étnicas, sociais, culturais ou de qualquer ordem passam a ser foco do discurso de inclusão escolar. Os comentários de Ainscow e os registros da UNESCO trazem à tona preocupações de ordem econômica direcionando as proposições acerca do atendimento às pessoas com necessidades educacionais especiais, como também registradas na década de 1970, por ocasião da implantação do CENESP.

Sob o impacto desses documentos e dentro de um conjunto de políticas sociais, um discurso de "educação inclusiva" toma corpo no país, de modo que profissionais que atuavam na Educação Especial passam, pouco a pouco, a utilizar o termo "inclusão" no lugar da bandeira da "integração". Essa mudança ocorre em vários países, como registrado por Ortiz González, ao analisar a inclusão na Espanha: "O termo inclusão está sendo adotado nos Estados Unidos, Canadá, Reino Unido, com a idéia de dar um passo à frente do que pretendeu a proposta integradora, que não tem servido para dar respostas à diversidade que se origina no seio da comunidade como se havia pretendido..." (GONZÁLES, 2005, p. 14).

Sem desconsiderar os movimentos em prol de situações menos segregadoras para as pessoas com deficiências, acreditamos que a implantação de uma política de "educação inclusiva" deve ser analisada no contexto complexo das políticas sociais nas sociedades capitalistas. Na história do país, a relação esta- 
belecida na legislação entre poder público, instituições privadas e rede de ensino, no que se refere às responsabilidades no atendimento de alunos com deficiências, caracterizou-se por uma complementaridade de ações ${ }^{19}$, sem superposição de serviços: os grupos privados, como as Sociedades Pestalozzi e as APAEs, responsabilizaram-se pelo atendimento aos alunos mais comprometidos e as classes especiais públicas atenderam a população menos comprometida. Essa relação de atendimentos fez com que as instituições especializadas assumissem uma posição de atores principais na Educação Especial brasileira. No decorrer dos anos 2000, essa posição começa a mudar quando o governo brasileiro, mais enfaticamente com o governo de Luiz Inácio Lula da Silva (2003-2006; 2007-2010), passa a implantar uma política denominada de "Educação Inclusiva". Pressionado por oferecer atendimento aos alunos que possuem deficiências, desde 2003 o Governo Federal opta pela matrícula dessa população em salas comuns de escolas públicas, acompanhado (ou não) de um atendimento educacional especializado, prioritariamente na forma de salas de recursos multifuncionais. Para sustentação dessa política, o Decreto 6.571/2008 dispõe sobre o atendimento educacional especializado e modifica as regras do Fundo de Manutenção e Desenvolvimento da Educação Básica e de Valorização dos Profissionais da Educação (FUNDEB) para garantir recursos àqueles alunos que efetivamente estejam matriculados em escolas públicas e recebendo atendimento educacional especializado. Em 2009, a Resolução n. ${ }^{\circ} 4$ institui as Diretrizes Operacionais para o Atendimento Educacional Especializado na Educação Básica, modalidade Educação Especial, e estabelece as formas possíveis desse atendimento:

Art. $1^{\circ}$ Para a implementação do Decreto ${ }^{\circ}$ 6.571/2008, os sistemas de ensino devem matricular os alunos com deficiência, transtornos globais do desenvolvimento e altas habilidades/superdotação nas classes comuns do ensino regular $\boldsymbol{e}$ no Atendimento Educacional Especializado (AEE), ofertado em salas de recursos multifuncionais ou em centros de Atendimento Educacional Especializado da rede pública ou de instituições comunitárias, confessionais ou filantrópicas sem fins lucrativos (BRASIL, 2009, grifos nossos).

A política de "Educação Inclusiva" vai materializando-se, também, com a constituição de um conjunto de programas e ações: "Programa Nacional de

\footnotetext{
${ }^{19}$ A regulamentação dos setores públicos e privados na educação brasileira é discutida por vários autores: Plank (1991), Jannuzzi (1997), entre outros.
} 
Formação Continuada de Professores na Educação Especial" e "Formação de Professores para o Atendimento Educacional Especializado", que atente a formação continuada de professores, prioritariamente na modalidade à distância; "Benefício de Prestação Continuada da Assistência Social" (BPC), que realiza acompanhamento e monitoramento de acesso e permanência nas escolas dos alunos beneficiários do BPC, até 18 anos; "Programa de Implantação de Salas de Recursos Multifuncionais"; "Escola Acessível”, para adaptação arquitetônica das escolas; "Programa Educação Inclusiva: Direito à Diversidade"; "Programa Incluir". Esses programas formam, hoje, um conjunto articulado que propõe a atingir os estabelecimentos de ensino dos diferentes municípios do país. Para mensurar a abrangência pretendida dessas ações, tomamos o Programa "Educação Inclusiva: Direto à diversidade" que, segundo a secretaria de Educação Especial do MEC, hoje atinge 5.564 municípios, que corresponde a 100\% dos municípios brasileiros. Com esse Programa, o Governo Federal brasileiro se compromete a fomentar a política de construção de "sistemas educacionais inclusivos", formando educadores num sistema de multiplicadores.

\section{Desafios da implantação de uma política nacional}

\section{A Secretaria de Educação Especial do MEC informa que}

Os resultados do Censo Escolar da Educação Básica de 2008 apontam um crescimento significativo nas matrículas da educação especial nas classes comuns do ensino regular. $\mathrm{O}$ índice de matriculados passou de $46,8 \%$ do total de alunos com deficiência, em 2007, para 54\% no ano passado ${ }^{20}$.

Segundo os dados apresentados pela Secretaria de Educação Especial, em princípio, a política proposta tem alcançado seus objetivos. No entanto, faz-se necessário olhar dentro da escola e identificar diferentes desafios. Como exemplo, optamos por apresentar o caso de um aluno que está matriculado em uma escola municipal da rede pública de um estado brasileiro no interior do

${ }^{20}$ Notícia retirada do portal do MEC, no subtítulo: "Política de Educação Inclusiva". Disponível em $<$ http://portal.mec.gov.br/index.php?option=com_content\&view=article\&id=12345\& ativo=711\&Itemid=709>. Acesso em: 13 de outubro de 2010. 
país $^{21}$. Trata-se de material coletado em pesquisa com auxílio de uma bolsista de iniciação científica no ano de 2009 (LEIJOTO; KASSAR, 2009). Trata-se de um município-polo do "Programa Educação Inclusiva: Direto à Diversidade" e tem aderido integralmente às propostas do Governo Federal através de editais e convênios. Escolhemos propositadamente um caso considerado "de sucesso" frente à escola: o aluno de $3^{\circ}$ ano (Rodrigo, que é cego) não apresenta problema de interação, é bem acolhido pela turma e é considerado bastante inteligente. Ele frequenta a escola em um período e recebe apoio especializado em sala de recurso em outro turno. Sua professora de sala comum leciona há 15 anos, é graduada em Pedagogia e tem Pós-Graduação em Educação Inclusiva. Participa, quando possível, das formações propostas pelo Programa Educação Inclusiva: Direto à Diversidade, dentre outras oferecidas pelo município. A professora da sala de recursos trabalha há 11 anos em sala de recurso e tem especialização em Educação Básica na perspectiva da Educação Inclusiva e formação específica na área da Deficiência Visual. Vamos ao diário de Campo:

A professora [na aula de geografia] havia trazido algumas folhas de seda para que as crianças desenhassem os mapas da América do Sul, do Brasil, e do Mato Grosso do Sul, para posteriormente pintá-los e serem colados em seus cadernos. Para o Rodrigo não havia preparado nada. Ele não poderia realizar essa atividade que exige o máximo da visão. Durante a realização das atividades pelos outros alunos, a professora improvisa e sai, no horário da aula, para tentar tirar cópia dos mapas, para que fosse colocado um barbante em torno deles. A professora ausentou-se da sala por cerca de 1 hora e meia e voltou com os mapas e o barbante. Nesse espaço de tempo, Rodrigo ficou sem nenhuma atividade. No retorno, verificou que o barbante que ela trouxe era muito grosso, o que a impedia de contornar o mapa e suas divisões com o material disponível. Por fim, sem sentir (por tato) o mapa e sem receber descrição oral da figura, Rodrigo ficou sem participar da aula de Geografia (REGISTRO DIÁRIO DE CAMPO, mar. 2009)

Vamos a outra situação:

[...] quando cheguei nesse dia, Rodrigo ainda estava fora da carteira sem nenhum material para trabalhar, embora no quadro já houvesse atividades

${ }^{21}$ Cidade de Corumbá em Mato Grosso do Sul. 
do livro didático descritas para serem feitas pelo resto da turma. [...] A professora pega o livro de História de um colega, resume riscando com caneta algumas partes do texto e começa a ditar para que Rodrigo escreva em Braille. No decorrer da aula, Rodrigo começa a reclamar pelo fato de que o texto que a professora havia "riscado" para ele copiar [em Braille] era muito grande, ele estava cansado, sua mão estava doendo de tanto escrever e que a reglete estava ruim. Então ele vai à sala de recurso e troca a reglete. Após a troca, ele continua a escrever e começa a "negociar" com a professora para terminar em sua casa o resto do texto. A professora não concorda e diz para ele copiar todo o texto independente de quantas folhas fossem. Rodrigo, a partir desse momento, se indigna e diz: - "Eu não vou terminar o texto, minha mão está doendo, nem adianta. Ninguém vai me obrigar! [...] Eu não vou ficar aqui me matando, escrevendo, se tem uma máquina aqui. A professora me disse que ia regular [a máquina] e até hoje não fez isso! Eu não vou escrever em Braille no reglete! Só se for na máquina!". Ele cobra o uso da máquina de escrever em Braille que a sala de recurso possui. Por sua reclamação, entende-se que a professora não havia ensinado ele a "mexer" na máquina porque faltava regular. A professora, nesse momento, vai até a coordenação e volta dizendo ao Rodrigo que havia conversado com a coordenadora para a aquisição de uma máquina. Rodrigo responde dizendo que já existe a máquina e a professora da sala de recurso havia falado que iria regular, mas ele mesmo "não havia nem visto a cor dela". A professora sai novamente, procura a professora da sala de recurso para confirmar a existência da máquina. Nesse momento, a professora viu, na sala, muitos materiais que ela nunca havia visto e tampouco em uso na escola. Entre eles, ela citou a bola de futebol com guiso e a própria máquina. Após todos esses acontecimentos e a partir da mobilização que o Rodrigo causou, a professora da sala de recurso afirmou que o Rodrigo irá começar a aprender a escrever na máquina de escrever em Braille no dia seguinte. (REGISTRO DIÁRIO DE CAMPO, abr. 2009).

Apesar de pontual e restrito, optamos por apresentar este caso, por acreditar ser, de certa forma, semelhante a situações que encontramos, por todo o país, citados em diversos trabalhos (LACERDA, 2006, 2007; PLETSCH, 2009; entre outros). Este caso faz-nos perceber que os desafios da implantação de uma política nacional de "educação inclusiva" são muitos. Estes desafios tornam-se evidentes mesmo quando estão cumpridas as exigências que os programas e projetos explicitam: salas reduzidas, acompanhamento em salas de recursos, adequação do espaço escolar, formação de professores, acolhimento da escola etc. 


\section{Considerações finais}

Documentos recentes da Secretaria de Educação Especial referem-se à construção de "sistemas educacionais inclusivos" em todos os níveis. Pelas ações implantadas, supomos que um "sistema educacional inclusivo" seja aquele que garanta o acesso ao estabelecimento educacional (garanta a matrícula e a permanência do aluno) e que ofereça, quando necessário, atendimento educacional especializado para complementar ou suplementar o atendimento escolar (oferecido prioritariamente em salas de recursos multifuncionais). Nessa proposta, as instituições especializadas, outrora atores principais da Educação Especial, têm a condição de locais para atendimento educacional especializado de caráter completar ou suplementar ${ }^{22}$.

A história de nossa educação constituiu-se de forma a separar os alunos: em normais e anormais; fortes e fracos etc. Dentro dessa forma de pensar a educação, muitas crianças estiveram longe das escolas públicas (não apenas crianças com deficiências). A política educacional atual impele a outras práticas escolares, diferentes das construídas historicamente. Para essa nova direção, o governo federal estabeleceu um caminho: a matrícula em classe comum e o apoio de atendimento educacional especializado para complementar ou suplementar a escolaridade. Para compreender essa escolha, acredito que seja necessário considerar os múltiplos determinantes da materialização da política educacional. Avelino, Brown e Hunter (2007, p. 209), com base em estudos de diferentes tendências, ao abordarem o debate sobre as políticas na contemporaneidade resumem a tensão: "os governos devem responder à globalização com uma política social orientada para o corte de gastos (eficiência) ou para a proteção do bem-estar das pessoas (compensação)". Ao olhar o conjunto das ações adotadas, verificamos as preferências do Governo Federal pela formação de educadores no sistema de multiplicadores e à distância. Essas escolhas pretendem otimizar os recursos atingindo o maior número de pessoas possível. As preocupações econômicas foram determinantes para adoção de políticas em outros momentos da história da educação brasileira, como parecem estar presentes agora. No entanto, ressaltamos o fato de que, muitas vezes, essas escolhas são incompatíveis para o estabelecimento da garantia de direitos sociais.

${ }^{22}$ A nota técnica SEESP/GAB/No 09/2010 esclarece que "O atendimento educacional especializado é realizado prioritariamente nas salas de recursos multifuncionais da própria escola ou em outra escola de ensino regular, no turno inverso da escolarização, podendo ser realizado também em centros de atendimento educacional especializado públicos e em instituições de caráter comunitário, confessional ou filantrópico sem fins lucrativos conveniadas com a Secretaria de Educação, conforme art. $5^{\circ}$ da Resolução CNE/CEB n. ${ }^{\circ} 4 / 2009 "$. 


\section{REFERÊNCIAS}

AINSCOW, M. Necesidades especiales en el aula. Guía para la formación del profesorado. Paris: UNESCO; Madrid: NARCEA, 1995.

ANTIPOFF, O. B. Educação do excepcional. Manual para professores. V. I. Guanabara: Edições Pestalozzi, 1974.

ARRUDA, E. E. de; KASSAR, M. C. M.; SANTOS, M. M. Educação Especial: o custo do atendimento de uma pessoa com necessidades especiais em instituições públicas estatal e não estatal, em MS, 2004. In: NERES, C. C.; LANCILLOTTI, S. S. P. (Orgs.). Educação especial em foco: questões contemporâneas. Campo Grande: UNIDERP, 2006. p. 89-116.

AVELINO, G; BROWN, D.; HUNTER, W. Internacionalização econômica, democratização e gastos sociais na América Latina, 1980-1999. In: HOCHMAN, G.; ARRETCHE, M.; MARQUES, E. (Orgs.). Políticas públicas no Brasil. Rio de Janeiro: FIOCRUZ, 2007.

BASBAUM, L. História Sincera da República. Das origens a 1889. 5. ed. São Paulo: Alfa-Omega, 1982.

BRASIL. Decreto 6.571, de 17 de setembro de 2008. Dispõe sobre o atendimento educacional especializado, regulamenta o parágrafo único do art. 60 da Lei no 9.394, de 20 de dezembro de 1996, e acrescenta dispositivo ao Decreto n. 6.253, de 13 de novembro de 2007 .

. Ministério da Educação e Cultura. Educação Especial. Cadastro Geral dos

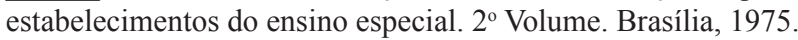
DF, 1993.

. Ministério da Educação. Plano Decenal de Educação para Todos. Brasília,

. Ministério de Administração Federal e da Reforma do Estado. Plano Diretor da Reforma do Aparelho do Estado. Brasília, 1995.

. Resolução n. 4, de 2 de outubro de 2009. Institui Diretrizes Operacionais para o Atendimento Educacional Especializado na Educação Básica, modalidade Educação Especial.

BUENO, J.G.S. Educação especial brasileira. Integração/segregação do aluno diferente. São Paulo: EDUC, 2004.

COSTA, A. da. Seleção de textos, 1868. In: FERREIRA, A. (Org.). Antologia de textos pedagógicos do século XIX português. V. III. Lisboa: Instituto Gulbenkian de Ciência, 1975. p. 179.

CURY, C. R. J.; HORTA, J. S. B.; FÁVERO, O. A relação educação-sociedade-estado pela mediação jurídico-constitucional. In: FÁVERO, O. (Org.). A educação nas constituintes brasileiras 1823-1988. Campinas: Papirus, 2001. p. 5-30. 
DECRETO 5.884 de 21 de abril de 1933. Revista de Educação, v. 2, 1933.

GALLAGHER, J. J. Planejamento da educação especial no Brasil. In: PIRES, N. Educação especial em foco. Rio de Janeiro: Centro Brasileiro de Pesquisas Educacionais, 1974.

HOBSBAWM, E. J. A era dos impérios. Rio de Janeiro: Paz e Terra, 1989.

JANNUZZI, G. A luta pela educação do deficiente mental no Brasil. São Paulo: Cortez: Autores Associados, 1985.

. A educação do deficiente no Brasil: dos primórdios ao início do século XXI. Campinas: Autores Associados, 2004.

. As políticas e os espaços para a criança excepcional. In: FREITAS, M. C. (Org.). História social da infância no Brasil. São Paulo: Cortez: USF, 1997.

LACERDA, C. B. F. de. A inclusão escolar de alunos surdos: o que dizem alunos, professores e intérpretes sobre esta experiência. Cadernos do CEDES, Campinas, v. 26, n. 69, p. 163-184, 2006.

LACERDA, C. B. F. de. O que dizem/sentem alunos participantes de uma experiência de inclusão escolar com aluno surdo. Revista Brasileira de Educação Especial, v. 13, p. 257-280, 2007.

LEIJOTO, C. P.; KASSAR, M. C. M. A organização didática do professor do ensino fundamental do processo de inclusão. Relatório de Iniciação Científica. Programa Institucional de Iniciação Científica: PIBIC: Universidade Federal de Mato Grosso do Sul, Conselho Nacional de Desenvolvimento Científico e Tecnológico, 2009.

MAGALHÃES, B. Tratamento e educação de crianças anormais de Inteligência. Rio de Janeiro: Tipografia do Jornal do Commercio, s/d.

MAZZOTTA, M. J. S. Educação Especial no Brasil: histórias e políticas. São Paulo: Cortez, 1996.

MONARCHA, C. Sobre Clemente Quaglio (1972 - 1948): notas de pesquisa patrono da cadeira no 31 "Clemente Quaglio". Boletim da Academia Paulista de Psicologia, v. 27, n. 2, p. 25-34, jul.-dez. 2007. Disponível em: <http://redalyc.uaemex.mx/redalyc/ pdf/946/94627205.pdf>. Acesso em: 02/03/2009.

GONZÁLEZ, M. C. O. Evolución histórica de la atención a las necesidades educativas especiales: una perspectiva desde la universidad. In: CONGRESO NACIONAL SOBRE UNIVERSIDAD Y DISCAPACIDAD, 1., Salamanca, ES, nov. 2005, p. 11-14.

PASCHOALICK, W. Análise do processo de encaminhamento de crianças das classes especiais para deficientes mentais, desenvolvido nas escolas de $1^{\circ}$ grau da delegacia de ensino de Marília. Dissertação (Mestrado em Educação) - Pontifícia Universidade Católica, São Paulo, 1981.

PINTO, N. S. A infância retardataria. (Ensaios de Orthophrenia). $2^{\text {a }}$ Ed. São Paulo: Escolas Profissionaes Salesianas, 1928. 
PIZZOLI, U. Psychologia Pedagogica. Revista de Ensino. Transcrição autorizada pelo autor do Estado de S. Paulo. Ano XIII, n. 3, dez. 1914.

PLANK, D. Os interesses público e privado na Educação Brasileira: males crônicos, soluções longínquas. Revista Brasileira de Estudos Pedagógicos, Brasília, v. 72, n. 170, p. 31-44, 1991.

PLETSCH, M. D. Repensando a inclusão escolar de pessoas com deficiência mental: diretrizes políticas, currículo e práticas pedagógicas. Tese (Doutorado em Educação) UERJ, Rio de Janeiro, 2009.

ROCHA, M. A. dos S. A educação do deficiente mental no Estado de São Paulo (18431971). I. Boletim SAPERE AUDE. N. 22, ano XV, 1979.

ROMANELLI, O. História da Educação no Brasil: 1930-1973. Petrópolis: Vozes, 1989.

SAVIANI, D. Escola e democracia. Edição comemorativa. Campinas: Autores Associados, 2008.

SCHNEIDER, D. Alunos excepcionais: um estudo de caso de desvio. In: VELHO, G. (Org.). Desvio e divergência. 2. ed. Rio de Janeiro: Zahar, 1977.

SILVA, A. G. O movimento apaeano no Brasil: Um estudo documental (1954-1994). Dissertação (Mestrado em Educação) - PUC, SP, 1995.

UNESCO. A educação no mundo. Vol. I. O ensino de primeiro e segundo graus. Seleção de textos extraídos da obra L'éducation dans le monde. Tradução de: GUEDES. Hilda de Almeida. V. 3, 1963. São Paulo: Saraiva: Ed. da Universidade de São Paulo, 1982.

VEIGA, C. G. Escola pública para os negros e os pobres no Brasil: uma invenção imperial. Revista Brasileira de Educação, v. 13, n. 39, p. 502-516, set-dez. 2008.

Texto recebido em 17 de dezembro de 2010 .

Texto aprovado em 31 de março de 2011. 